\title{
HIGHER PRO-INFLAMMATORY DIET AND WORSE NUTRITIONAL STATUS DURING CHEMOTHERAPY: A PROSPECTIVE STUDY WITH BREAST CANCER WOMEN
}

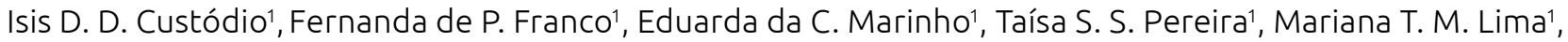
Maria del Carmen B. Molina', Carlos E. Paiva', Yara C. de P. Maia ${ }^{1}$

${ }^{1}$ Universidade Federal de Uberlândia - Uberlândia (MG), Brazil.

This prospective study aimed to evaluate, for the first time in the literature, the association between the Dietary Inflammatory Index (DII) score and the average consumption of food groups (grams/day), at three times of chemotherapy (CT), beginning (T0), during (T1) and after the end of treatment (T2), as well as the relationship between the modification of the nutritional status and those variables. Anthropometric and dietary assessments of 55 women with breast cancer undergoing CT were performed, the latter by applying nine nonconsecutive $24 \mathrm{~h}$ dietary recalls, three at each time. Friedman's test has showed that weight, Body Mass Index and waist circumference increased significantly $(p=0.008, p=0.009$ and $p=0.030$, respectively), indicating a worse nutritional status in T2 when compared to T0. The Waist-to-Height Ratio and Waist-Hip Ratio presented weak and positive Pearson's correlations with DII in T1 ( $r=0.267, p=0.026)$ and in T2 ( $r=0.298, p=0.027)$, indicating that those women with higher abdominal fat deposition presented more pro-inflammatory diet. Consumption of Poultry and Eggs $[F(2,108)=3.358 ; \mathrm{p}=0.038]$ was significantly higher in $\mathrm{T} 1$ when compared to T2, while Total Fruits $\left[\chi^{2}(2)=13.237 ; p=0.001\right]$ and Total Vegetables $\left[\chi^{2}(2)=17.491 ; p<0.001\right)$ presented higher consumption in T0 compared to T1 and T2. The IID score increased considerably throughout the treatment, indicating that diet became more pro-inflammatory $\left[\chi^{2}(2)=61.127 ; \mathrm{p}<0.001\right]$. Total Fruits $\left[\mathrm{T} 0: \mathrm{R}^{2}=0.208, \mathrm{p}=0.001 ; \mathrm{T} 1: \mathrm{R}^{2}=0.095, \mathrm{p}<0.001 ; \mathrm{T} 2: \mathrm{R}^{2}=0.120, \mathrm{p}=0.012\right]$ and Total Vegetables [T0: $\left.\mathrm{R}^{2}=0.284, \mathrm{p}<0.001 ; \mathrm{T} 1: \mathrm{R}^{2}=0.365, \mathrm{p}<0.001 ; \mathrm{T} 2: \mathrm{R}^{2}=0.580, \mathrm{p}<0.001\right)$ showed significant predictive capacity of the IID in the three times; while Total Grains in T1 $\left(\mathrm{R}^{2}=0.084, \mathrm{p}=0.033\right)$ and T2 $\left(\mathrm{R}^{2}=0.118, \mathrm{p}=0.013\right)$; and Simple Sugars, in $\mathrm{T} 0\left(\mathrm{R}^{2}=0.137, \mathrm{p}=0.006\right)$ and $\mathrm{T} 1\left(\mathrm{R}^{2}=0.126, \mathrm{p}=0.008\right)$. We suggest that the adoption of healthy eating habits associated with healthy nutritional status maintenance may reduce the chronic inflammation and the risk of recurrence and comorbidities, reinforcing the importance of multi-professional follow-up undergoing CT. 